\title{
Examination of Patient Transfer Criteria to Higher Medical Institutions After Emergency Endoscopy at a Private Medical Facility Without Hospital Beds
}

Kazuhiko Obata ( $\square$ kazuobata0719@gmail.com)

Onaka-kai Onaka Clinic

Kan Uchiyama

The Jikei University Kashiwa Hospital

Takenori Hada

Onaka-kai Onaka Clinic

Ryuzo Murai

Onaka-kai Onaka Clinic

\section{Research Article}

Keywords: comorbidities; endoscopy; patient transfer; private facility; vital signs

Posted Date: January 18th, 2022

DOI: https://doi.org/10.21203/rs.3.rs-1188564/v1

License: (c) (1) This work is licensed under a Creative Commons Attribution 4.0 International License. Read Full License 


\begin{abstract}
Background: Because the clinical course of gastrointestinal bleeding varies, urgent judgments regarding the severity of a patient's condition, indications for endoscopic hemostasis, and transfer to a higher medical institution are needed at private medical facilities without hospital beds. The present study aimed to evaluate the characteristics of patients with vital sign fluctuations during emergency endoscopy for gastrointestinal bleeding and experiencing rebleeding within 30 days after initial endoscopy. We then investigated criteria for transferring patients to higher medical institutions based on the results.
\end{abstract}

Methods: We retrospectively evaluated the characteristics of 91 patients who underwent emergency endoscopy for gastrointestinal bleeding at our facility without hospital beds between January 2016 and September 2020. The patients were divided into 2 groups: 13 with vital sign fluctuations during emergency endoscopy and/or rebleeding within 30 days after an initial endoscopy as the required transfer group and 78 without either as the nonrequired transfer group.

Results: No significant differences in age, sex, location, or endoscopic treatment were observed between the 2 groups. However, the prevalence of comorbidities was significantly higher in the required transfer group $(P<0.001)$. Moreover, multivariate logistic regression analysis identified comorbidities (odds ratio [OR], 10.646; 95\% confidence interval [CI], 2.868-68.330; $P=0.001$ ) as an independent risk factor for vital sign fluctuation and/or rebleeding.

Conclusions: These findings suggest that comorbidity presence is a poor prognostic factor in patients with gastrointestinal bleeding, for whom transfer to higher medical institutions needs to be actively considered.

\title{
Trial registration
}

Participants were retrospectively registered.

\section{Background}

With the aging of the Japanese population, the rate of gastrointestinal (GI) bleeding as a background for the administration of antithrombotic medication and nonsteroidal anti-inflammatory drugs (NSAIDs) has increased [1, 2]. In countries or regions where the population is aging, such as in Japan, many patients are middle-aged or elderly and/or have comorbidities, and the number of these patients is expected to increase in the future. As the clinical course of $\mathrm{Gl}$ bleeding varies, urgent judgments regarding the severity of a patient's condition, indications for endoscopic hemostasis, and transfer to a higher medical institution are required at private medical facilities without hospital beds. In the present study, we retrospectively evaluated the characteristics of patients who underwent emergency endoscopy for GI bleeding to clarify appropriate criteria for transferring patients to higher medical institutions.

\section{Methods}

\section{Study design and patient selection}

We performed a retrospective analysis of the characteristics of 91 patients for whom upper and lower GI bleeding was suspected and emergency endoscopy was performed between January 2016 and September 2020 at our private medical facility without hospital beds. Each patient was 18 years or older and underwent emergency endoscopy to confirm recent onset of GI bleeding. The following clinical and endoscopic data for patients with GI bleeding were collected for all 91 patients: age, sex, comorbidities, location, endoscopic treatment, and antithrombotic medication, including antiplatelet medication and anticoagulant medication. We designated patients with vital sign fluctuation (VSF) during emergency endoscopy and/or rebleeding after initial endoscopy as candidates for transfer. Rebleeding was defined as recurrent hematemesis, hematochezia and melena observed within 30 days after initial endoscopy and demonstrated by a second endoscopy. VSF was defined as one of the following: (1) systolic blood pressure $<90 \mathrm{mmHg}$ or a decrease of $30 \mathrm{mmHg}$ or more from normal systolic blood pressure, (2) heart rate $>100$ beats/minute, and (3) respiratory rate $>22$ breaths/minute. Ninety-one patients were divided into 2 groups: required transfer (reqTr), a group of patients with VSF during emergency endoscopy and/or rebleeding; and nonreqTr, a group of patients without VSF.

\section{Endoscopic capacity}


There were 55,350 gastrointestinal examinations performed from January 2016 to September 2020: 32,030 upper GI endoscopies and 23,320 lower $\mathrm{GI}$ endoscopies. We utilized four endoscopic systems (Evis Lucera Elite system ${ }^{\circledR}$; Olympus), 13 upper GI

videoscopes (GIF-H290, GIF-H290Z, GIF-Q260, GIF-XP260, GIF-1200N; Olympus), and 14 lower GI videoscopes (CF-H290I, PCF-H290I, PCF-H290ZI, PCF-PQ260 L, CF-Q260Al, PCF-Q260Al; Olympus). The health care personnel consisted of 3 full-time doctors (2 gastroenterological surgeons, 1 gastroenterologist), 31 part-time doctors (19 gastroenterological surgeons, 12 gastroenterologists), 18 nurses, and 7 clinical laboratory technologists involved in endoscopic treatment. Almost all of the doctors were certified as specialists of the Japan Gastroenterological Endoscopy Society. The endoscopic instruments included snares, forceps, endoscopic clips, retrieval nets, injectors, and electrosurgical units. For endoscopic hemostasis, endoscopic clips and contact thermal therapy with bipolar electrocautery probes were used in our facility.

\section{Statistical analysis}

SPSS for Windows software (SPSS Japan, Tokyo, Japan) was used for statistical analyses. We performed an unpaired $t$-test for comparisons between two groups for continuous variables, Fisher's exact test for comparisons between two groups for categorical variables, and a logistic regression analysis to identify risk factors for anomalous vital signs. P values $<0.05$ were considered to be significant.

\section{Ethics}

The present study was approved by the Onaka Clinic Ethics Committee (OCIRB-2021-001) on October 24th, 2020.

\section{Results}

First, we reviewed the clinical features of patients with GI bleeding who underwent emergency endoscopy. Their clinical characteristics are summarized in Table 1. The average age of the patients was $59.1 \pm 17.9$ years. There were 45 females and 46 males, with no sex differences in average age ( $62.5 \pm 16.7$ vs. $55.7 \pm 18.7$, respectively, $\mathrm{P}=0.07)$. Among the 91 patients examined, 33 (36.3\%) had comorbidities, 13 (14.3\%) were taking antithrombotic medication, 11 (12.1\%) had VSF, 22 (24.2\%) were transferred to higher medical institutions, and 5 (5.5\%) experienced rebleeding within 30 days after initial endoscopy. The most common comorbidity was hypertension ( 21 cases, $23.1 \%$ ), followed by atrial fibrillation (4 cases, $4.4 \%$ ), hypertension/diabetes (3 cases, $3.3 \%$ ), hypertension/atrial fibrillation (2 cases, $2.2 \%$ ), hypertension/cerebral infarction, atrial fibrillation/cerebral infarction, and hypertension/rheumatoid arthritis (1 case, $1.1 \%$ ). The number of patients receiving antithrombotic treatment was similar to that receiving antiplatelet and anticoagulant drugs ( 6 cases, $6.6 \%$ and 5 cases, $5.5 \%$ ), with two patients receiving two drugs in combination. Seventeen patients (18.7\%) underwent endoscopic treatment, and the clipping method was applied in all cases. The main causes of gastrointestinal bleeding were ischemic enteritis (17 cases, $18.7 \%$ ) and gastrointestinal malignancies (17 cases, 18.7\%), followed by diverticular bleeding (14 cases, $15.4 \%)$, post-EMR bleeding (11 cases, $12.1 \%)$, and peptic ulcers (10 cases, $11 \%)$. Lower GI bleeding (LGIB) accounted for approximately $70 \%$ of cases. 
Table 1

Characteristics of patients undergoing emergency endoscopic examinations for acute gastrointestinal bleeding.

\begin{tabular}{|c|c|}
\hline Characteristics & $\mathbf{N}(\%)$ \\
\hline Overall & $91(100)$ \\
\hline Average age $( \pm S D)$ & $59.1 \pm 17.9$ \\
\hline Sex (male/female) & $46 / 45$ \\
\hline \multicolumn{2}{|l|}{ Comorbidities: } \\
\hline None & $58(63.7)$ \\
\hline Hypertension & $21(23.1)$ \\
\hline Atrial fibrillation & $4(4.4)$ \\
\hline Hypertension/Diabetes & $3(3.3)$ \\
\hline Hypertension/Atrial fibrillation & $2(2.2)$ \\
\hline Hypertension/Cerebral infarction & $1(1.1)$ \\
\hline Atrial fibrillation/Cerebral infarction & $1(1.1)$ \\
\hline Hypertension/Rheumatoid arthritis & $1(1.1)$ \\
\hline \multicolumn{2}{|l|}{ Antithrombotic medication: } \\
\hline Antiplatelet medication & $6(6.6)$ \\
\hline Anticoagulant medication & $5(5.5)$ \\
\hline Combination of antiplatelet and anticoagulant medication & $2(2.2)$ \\
\hline \multicolumn{2}{|l|}{ Cause of bleeding based on endoscopic findings: } \\
\hline Ischemic enteritis & $17(18.7)$ \\
\hline Gastrointestinal malignancy & $17(18.7)$ \\
\hline Diverticular bleeding & $14(15.4)$ \\
\hline Post-EMR bleeding & $11(12.1)$ \\
\hline Gastric/Duodenal ulcer & $10(11.0)$ \\
\hline Mallory Weiss tear & $8(8.8)$ \\
\hline Infectious enteritis & $4(4.4)$ \\
\hline Ulcerative colitis & $3(3.3)$ \\
\hline Hemorrhoidal bleeding & $2(2.2)$ \\
\hline Reflux esophagitis & $2(2.2)$ \\
\hline Postbiopsy bleeding & $1(1.1)$ \\
\hline Drug-induced enteritis & $1(1.1)$ \\
\hline Duodenal malignant lymphoma & $1(1.1)$ \\
\hline Vital signs fluctuation & $11(12.1)$ \\
\hline Transfer & $22(24.2)$ \\
\hline Endoscopic treatment & $17(18.7)$ \\
\hline Rebleeding & $5(5.5)$ \\
\hline
\end{tabular}

Page 4/9 


\section{Examination of patient transfer criteria to higher medical institutions}

We examined criteria for patient transfer to higher medical institutions. Using our database, we identified 13 candidates who met the transfer criteria. Table 2 shows a comparison of the characteristics between the reqTr and nonreqTr groups. Although no significant differences in age, sex, location, endoscopic treatment, or antithrombotic medication were observed between the two groups, the proportion of patients with comorbidities was significantly higher in the reqTr group than in the nonreqTr group (84.6\% vs. $28.2 \%$; P $<0.001)$.

Table 2

Comparison of characteristics between candidates and noncandidates for transfer.

\begin{tabular}{|llll|}
\hline & Candidates $(\mathbf{n}=\mathbf{1 3})$ & Noncandidates(n=78) & P value \\
\hline Age $\geq 65$ years (\%) & $7(53.8 \%)$ & $33(42.3 \%)$ & 0.316 \\
\hline Sex (male:female) & $7: 6$ & $39: 39$ & 0.517 \\
\hline Location (Upper GI:Lower GI) & $5: 8$ & $18: 60$ & 0.198 \\
\hline Comorbidity (\%) & $11(84.6 \%)$ & $22(28.2 \%)$ & $<0.001$ \\
\hline Antithrombotic medication (\%) & $4(30.8 \%)$ & $9(11.5 \%)$ & 0.086 \\
\hline Endoscopic treatment (\%) & $3(23.1 \%)$ & $14(17.9 \%)$ & 0.454 \\
\hline
\end{tabular}

To identify risk factors for VSF and rebleeding, which are triage indicators for patients requiring transfer, logistic regression analysis was performed using VSF and rebleeding as the dependent variables and age, comorbidities, and antithrombotic medication as explanatory variables. Based on the variable reduction method, the only independent risk factor was comorbidities (odds ratio: 10.646, 95\% Cl: 2.868-68.330; $\mathrm{P}=0.001$ ) (Table 3). Similar results were obtained when comorbidities were analyzed by focusing on hypertension.

Table 3

Risk factors for vital sign fluctuation and/or rebleeding in multivariate analysis.

\begin{tabular}{|c|c|c|c|c|c|c|c|}
\hline & \multicolumn{4}{|c|}{ Logistic regression analysis } & \multicolumn{3}{|c|}{ Backward elimination method } \\
\hline & Variable & $\begin{array}{l}\text { Partial } \\
\text { regression } \\
\text { coefficient }\end{array}$ & OR $(95 \% \mathrm{Cl})$ & $\begin{array}{l}P \\
\text { value }\end{array}$ & $\begin{array}{l}\text { Partial } \\
\text { regression } \\
\text { coefficient }\end{array}$ & OR $(95 \% \mathrm{Cl})$ & $\begin{array}{l}P \\
\text { value }\end{array}$ \\
\hline Age $\geq 65$ years & & -0.847 & $\begin{array}{l}0.429(0.095- \\
1932)\end{array}$ & 0.270 & & & \\
\hline $\begin{array}{l}\text { Antithrombotic } \\
\text { medication }\end{array}$ & Absence/Presence & 0.019 & $\begin{array}{l}1.019(0.216- \\
4.800)\end{array}$ & 0.981 & & & \\
\hline Comorbidity & Absence/Presence & 3.067 & $\begin{array}{l}21.473(3.451- \\
133.592)\end{array}$ & 0.001 & 2.639 & $\begin{array}{l}14.000(2.868- \\
68.330)\end{array}$ & 0.001 \\
\hline
\end{tabular}

Considering the above results, the clinical features of 5 cases of rebleeding were examined in detail (Table 4). The average age of the 3 male and 2 female patients with rebleeding was 69.6 years; upper GI rebleeding occurred in 3 patients, and lower GI rebleeding occurred in 2. There were 4 cases with comorbidities, and 2 of them were not transferred at the discretion of the endoscopist because VSF did not occur during or after endoscopy. All patients with upper GI bleeding had an ulcer with an exposed blood vessel, and clipping hemostasis was performed as the initial treatment at our private facility. In the two cases of anastomotic ulcers, blood transfusion and additional endoscopic treatment were required because bleeding was not suppressed, even after transfer. Two cases of lower GI bleeding involved advanced rectal cancer and diverticular bleeding. The patient with rectal cancer had severe anemia $(\mathrm{Hb} 5.7 \mathrm{~g} / \mathrm{dl})$ and decreased blood pressure, and it was difficult to conservatively stop bleeding; therefore, this patient required transfusion and surgery after transfer. In the diverticular bleeding case, anticoagulant and antiplatelet drugs were used in combination for hypertension, atrial fibrillation, and ischemic heart disease, and the bleeding point was not identified by initial 
endoscopy, resulting in conservative treatment. Rebleeding occurred 2 days later; exposed blood vessels were confirmed in a large diverticulum, and the bleeding was stopped by directly grasping at the base of the diverticulum.

Table 4

Examination of rebleeding cases.

\begin{tabular}{|c|c|c|c|c|c|c|c|c|c|}
\hline & Age & Sex & $\begin{array}{l}\text { Causative } \\
\text { disease }\end{array}$ & Comorbidities & $\begin{array}{l}\text { Antithrombotic } \\
\text { medication }\end{array}$ & $\begin{array}{l}\text { Vital sign } \\
\text { Fluctuation }\end{array}$ & $\begin{array}{l}\text { Initial } \\
\text { treatment }\end{array}$ & $\begin{array}{l}\text { Treatment } \\
\text { for } \\
\text { rebleeding }\end{array}$ & Transfer \\
\hline \multirow[t]{2}{*}{$\begin{array}{l}\text { Case } \\
1\end{array}$} & 61 & Male & $\begin{array}{l}\text { Diverticular } \\
\text { bleeding }\end{array}$ & Hypertension & + & - & - & Clipping & - \\
\hline & & & & \multicolumn{6}{|l|}{ Atrial fibrillation } \\
\hline $\begin{array}{l}\text { Case } \\
2\end{array}$ & 68 & Male & $\begin{array}{l}\text { Rectal } \\
\text { carcinoma }\end{array}$ & - & - & + & - & Surgery & + \\
\hline \multirow[t]{2}{*}{$\begin{array}{l}\text { Case } \\
3\end{array}$} & 81 & Female & Gastric ulcer & Hypertension & - & - & Clipping & Clipping & - \\
\hline & & & \multicolumn{7}{|c|}{ (Dieulafoy's lesion) } \\
\hline $\begin{array}{l}\text { Case } \\
4\end{array}$ & 55 & Male & $\begin{array}{l}\text { Upper } \\
\text { anastomotic } \\
\text { ulcer }\end{array}$ & Hypertension & - & + & Clipping & Clipping & + \\
\hline $\begin{array}{l}\text { Case } \\
5\end{array}$ & 83 & Female & $\begin{array}{l}\text { Upper } \\
\text { anastomotic } \\
\text { ulcer }\end{array}$ & Hypertension & - & + & Clipping & Clipping & + \\
\hline
\end{tabular}

\section{Discussion}

In this study, VSF during emergency endoscopy and rebleeding within 30 days after first endoscopy were defined as indicators for transfer to higher medical institutions. Hence, the presence of comorbidities extracted as the independent risk factor for these indicators may be important for rapid triage of patients requiring transfer. Most patients with VSF or rebleeding have peptic ulcers, diverticular bleeding, and ischemic enteritis with comorbidities, possibly because they have more severe hemorrhage, resulting in lower systolic and diastolic blood pressure, tachycardia, and increased respiratory rate. When faced with VSF and uncontrollable bleeding despite appropriate hemostatic treatments during emergency endoscopy, it is critically important to both understand and stabilize the patient's general conditions and to make a clinical decision regarding transfer of urgent patients to higher medical institutions. Many studies have examined the severity of upper and lower gastrointestinal bleeding and predictive tools for proper acute triage settings. The Glasgow-Blatchford Score (GBS), which is designed to predict the need for a blood transfusion, intervention to control bleeding, rebleeding, or death, and AIMS65, which aims to predict all-cause mortality, are scoring systems for treatment and emergency transfer priorities for patients with upper GI bleeding [3, 4]. The cohort study by Horibe et al. [5] advocates the Horibe gAstRointestinal BleedING scoRe (HARBINGER), a score of 3 variables (1 point each for absence of daily proton pump inhibitor use in the week before the index presentation, shock index [heart rate/systolic blood pressure $\geq 1$ ], and blood urea nitrogen/creatinine $\geq 30$ ) that is superior to the GBS and AIMS65 in terms of simplicity and accuracy as a triage tool to identify patients with upper GI bleeding who require hospitalization and emergency endoscopy. Patients with a HARBINGER $\geq 1$ are identified as candidates for hospitalization. In our study, it was found that all cases of upper GI bleeding with VSF during emergency endoscopy corresponded to the shock index (heart rate/systolic blood pressure $\geq 1$ ), suggesting that the decision to set VSF as a criterion for transferring to higher medical institutions was valid. Rebleeding acts as a sign of instability, and emergency transfer should be considered for patients with high-risk upper GI bleeding. The location on the lesser curvature of the stomach or on the posterior or superior wall of the duodenum, size over $2 \mathrm{~cm}$ in diameter, and presence of high-risk lesions (spurting, oozing blood, nonbleeding visible vessel, and an adherent clot) have been reported as endoscopic predictors of increased risk of GI rebleeding [6]. On the other hand, clinical predictors of GI rebleeding include comorbidity, anemia (low hemoglobin levels), need for transfusion, finding of fresh red blood during a rectal examination or during nasogastric suction or vomiting, melena, advanced age (older than 65 years), syncope or hemodynamic instability, and deterioration of overall health [6]. 
With regard to LGIB, Strate et al. [7] reported the following seven clinical risk factors associated with severe LGIB (defined as continuous and/or recurrent bleeding): tachycardia, low systolic blood pressure, syncope, nontender abdominal examination, bleeding per rectum within the first $4 \mathrm{~h}$ of medical assessment, use of aspirin, and more than two active comorbidities. Patients with 3 or more of these risk factors are at a high risk of severe bleeding. Furthermore, Aoki et al. [8] described a predictive model of severe LGIB (NOBLADS score), i.e., NSAID use, no diarrhea, no abdominal tenderness, systolic blood pressure $\leq 100 \mathrm{mmHg}$, albumin level < $3.0 \mathrm{~g} / \mathrm{dL}$ nonaspirin antiplatelet drug use, Charlson comorbidity index score $\geq 2$, and syncope. These studies suggest that hemodynamic instability and comorbidities are important factors associated with the severity and rebleeding of upper and lower $\mathrm{GI}$ bleeding. Moreover, in lower GI bleeding, the use of antithrombotic medication is associated with increased severity. Chong et al. [9] reported that patients taking aspirin were 2.6 times more likely to develop severe lower GI bleeding. Many private facilities, such as ours, do not have an on-site laboratory and cannot perform blood tests on the same day. Thus, it is necessary to triage patients who need urgent hospitalization with the minimum necessary information. In private facilities, extracting low-risk patients from among those with GI bleeding may prevent unnecessary transfers, reduce medical costs, and efficiently utilize medical resources.

The present study had several limitations. This was a single-center retrospective study with a small number of cases. In addition, well-known rebleeding risk factors may have been taken into consideration when deciding whether to transfer patients after endoscopy. Moreover, as our facility is a private clinic, the number of critically severe cases was small, and options for endoscopic treatment were limited. We will continue to accumulate cases and strive to establish optimal transfer standards for emergency patients with GI bleeding who are at high risk of sudden changes in their physical condition.

\title{
Conclusions
}

The presence of comorbidities with upper and lower gastrointestinal bleeding is associated with VSF during emergency endoscopy and/or rebleeding within 30 days of the first endoscopy and might be a factor influencing poor prognosis. VSF be an absolute indicator for transfer to higher medical institutions after emergency endoscopy in a private facility without beds. Overall, patients with comorbidities are at risk of significant VSF and rebleeding and should be actively considered for transfer after emergency endoscopy.

\section{Abbreviations}

\author{
EMR \\ Endoscopic mucosal resection \\ GBS \\ Glasgow-Blatchford score \\ LGIB \\ Lower gastrointestinal bleeding \\ NSAIDs \\ Nonsteroidal anti-inflammatory drugs \\ OR \\ Odds ratio \\ $\mathrm{Cl}$ \\ Confidence interval \\ VSF \\ vital sign fluctuation
}

\section{Declarations}

\section{Acknowledgements}

Not applicable.

\section{Author contributions}


KO: curation of data; analysis and interpretation of data; drafting of the manuscript; project administration

KU: study concept and design; formal analysis; methodology

TH: project administration

RM: project administration; supervision

All authors read and approved the final manuscript.

\section{Funding}

This study has no funding support.

Availability of data and materials

The datasets used and / or analyzed during the current study are available from the corresponding authors upon reasonable request.

All data generated or analyzed during this study are included in this published article and its supplementary information files.

\section{Ethics approval and consent to participate}

All procedures were performed in accordance with the ethical standards detailed in Declaration of Helsinki. This study was reviewed and approved by the Onaka Clinic Ethics Committee (OCIRB-2021-001) on October 24th, 2020. Informed consent for this study was waived by the Onaka Clinic Ethics Committee (OCIRB-2021-001) on October 24th, 2020 because the study was conducted retrospectively.

\section{Consent for publication}

Not applicable.

\section{Competing interests}

The authors declare that there are no conflicts of interest associated with this manuscript.

\section{Author information}

\section{Affiliations}

\section{Onaka-kai Onaka Clinic, Hachioji, Tokyo, Japan}

Kazuhiko Obata, Takenori Hada, Ryuzo Murai

\section{Division of Gastroenterology and Hepatology, Department of Internal Medicine, The Jikei University Kashiwa Hospital, Kashiwa, Chiba, Japan}

Kan Uchiyama

\section{References}

1. Sugisaki N, Iwakiri R, Tsuruoka N, Sakata Y, Shimoda R, Fujimoto S, et al. A case-control study of the risk of upper gastrointestinal mucosal injuries in patients prescribed concurrent NSAIDs and antithrombotic drugs based on data from the Japanese national claims database of 13 million accumulated patients. J Gastroenterol. 2018;53:1253-60.

2. Aoki T, Hirata Y, Yamada A, Koike K. Initial management for acute lower gastrointestinal bleeding. World J Gastroenterol. 2019;25:69-84. 
3. Blatchford O, Murray WR, Blatchford M. A risk score to predict need for treatment for upper-gastrointestinal haemorrhage. Lancet. 2000;356:1318-21.

4. Saltzman JR, Tabak YP, Hyett BH, Sun X, Travis AC, Johannes RS. A simple risk score accurately predicts in-hospital mortality, length of stay, and cost in acute upper GI bleeding. Gastrointest Endosc. 2011;74:1215-24.

5. Horibe M, Iwasaki E, Bazerbachi F, Kaneko T, Matsuzaki J, Minami K, et al. Horibe Gl bleeding prediction score: a simple score for triage decision-making in patients with suspected upper GI bleeding. Gastrointest Endosc. 2020;92:578-88.e4.

6. Greenspoon J, Barkun A, Bardou M, Chiba N, Leontiadis GI, Marshall JK, et al. Management of patients with nonvariceal upper gastrointestinal bleeding. Clin Gastroenterol Hepatol. 2012;10:234-9.

7. Strate LL, Orav EJ, Syngal S. Early predictors of severity in acute lower intestinal tract bleeding. Arch Intern Med. 2003;163:83843.

8. Aoki T, Nagata N, Shimbo T, Niikura R, Sakurai T, Moriyasu S, et al. Development and validation of a risk scoring system for severe acute lower gastrointestinal bleeding. Clin Gastroenterol Hepatol. 2016;14:1562-70.e2.

9. Chong V, Hill AG, MacCormick AD. Accurate triage of lower gastrointestinal bleed (LGIB) - A cohort study. Int J Surg. 2016;25:19-23.

\section{Supplementary Files}

This is a list of supplementary files associated with this preprint. Click to download.

- Data.xlsx 